\title{
The Effects of a STEM Approach on Preservice Elementary Teachers' Subject Matter Knowledge about Sound
}

\author{
Marisa Sofia Monteiro Correia ${ }^{\mathrm{B}} \mathrm{a}, \mathrm{b}$ \\ Mónica Luísa Mendes Baptista ${ }^{\mathrm{c}, \mathrm{d}}$ \\ ${ }^{a}$ Instituto Politécnico de Santarém (IPSantarem), Escola Superior de Educação, Santarém, Portugal \\ ${ }^{\mathrm{b}}$ Centro de Investigação em Qualidade da Vida (CIEQV), Rio Maior, Portugal \\ ${ }^{\mathrm{c}}$ Universidade de Lisboa, Instituto de Educação, Lisboa, Portugal \\ ${ }^{d}$ UIDEF, Instituto de Educação, Lisboa, Portugal
}

Received for publication on 11 Nov. 2020. Accepted after review on 18 Nov. 2021. Designated editor: Renato P. dos Santos

\begin{abstract}
Background: STEM education has been in focus in recent years given its innumerable potential for developing diverse skills and encouraging the pursuit of careers in the STEM areas. In this way, since initial training, it is crucial to create conditions for preservice teachers (PSTs) in STEM experiences that encourage the development of their subject matter knowledge (SMK). Objectives: This study aims to examine the effects of STEM activities centred on inquiry-based learning on PSTs' SMK about sound phenomena and concepts. Design: This is a qualitative and interpretative study. Setting and Participants: The participants are nine preservice teachers studying in a Portuguese higher education institution. Data collection and analysis: Two data collection methods were used: (i) students' productions developed through six STEM activities that included sound-related concepts, such as sound vibration, wave, transmission, velocity, and loudness and (ii) field notes. To analyse the data, we used an inductive strategy of content analysis. Results: Results revealed that the preservice teachers initially misconceived sound and had their subject matter knowledge improved after the activities. Conclusions: STEM approach favoured an active involvement of PSTs in their learning, connecting contents to real-life situations.

Keywords: STEM activities; Inquiry-based learning; Preservice teachers; Subject matter knowledge.
\end{abstract}

Corresponding author: Marisa Sofia Monteiro Correia. Email: marisa.correia@ese.ipsantarem.pt 


\section{Os Efeitos de uma Abordagem STEM no Conhecimento de Conteúdo de Futuros Professores sobre o Som}

\section{RESUMO}

Contexto: A Educação STEM tem estado em destaque nos últimos anos devido ao seu potencial para o desenvolvimento de competências diversas e para o incentivo ao prosseguimento de carreiras nas áreas STEM. Desse modo, é fundamental, desde a formação inicial, criar condições para envolver os futuros professores em experiências com as STEM que estimulem o desenvolvimento do seu conhecimento de conteúdo. Objetivos: Este estudo tem como objetivo analisar o efeito das atividades STEM, com enfoque na aprendizagem baseada em investigação, no conhecimento de conteúdo de futuros professores sobre o tópico do som. Design: Foi utilizado um estudo qualitativo e interpretativo. Ambiente e participantes: Os participantes são nove futuros, a frequentar uma Escola Superior de Educação Portuguesa. Coleta e análise de dados: Dois métodos de coleta de dados foram usados: (i) produções dos alunos desenvolvidas por meio de seis atividades STEM que incluíram conceitos sobre som, como produção do som, ondas sonoras, transmissão do som, velocidade do som e intensidade sonora e (ii) notas de campo. Para analisar os dados, foi utilizada uma estratégia indutiva de análise de conteúdo. Resultados: Os resultados mostraram que os futuros professores inicialmente revelam conceções erradas sobre os conceitos de som e apontam para uma evolução no seu conhecimento de conteúdo após as atividades. Conclusões: A abordagem STEM favoreceu um envolvimento ativo dos futuros professores na sua aprendizagem, estabelecendo conexões entre os conteúdos e situações reais.

Palavras-chave: aprendizagem baseada em investigação; atividades STEM; conhecimento de conteúdo; futuros professores.

\section{INTRODUCTION}

Research has given increasing attention to STEM education, making the scientific community's interest in this area clear (Li et al., 2020). STEM practices in the classrooms allow students to understand the importance of scientific and technological developments, which occur very quickly, and pursue STEM areas or careers (Chiu \& Duit, 2011). Several studies show the potential of STEM education to promote students' curiosity about natural phenomena (Crippen \& Antonenko, 2018; Moore et al., 2015), to increase their motivation and interest in science (Chittum et al., 2017; Shahali et al., 2017; Toma \& Greca, 2018), and to increase their intention to pursue careers in STEM areas (Christensen \& Knezek, 2017; Kitchen et al., 2018; Wang, 2013). In addition, STEM education promotes the development of several skills, namely problem solving, critical thinking and creativity (Guthrie et al., 2000). 
However, despite the potential and benefits of STEM education for students, studies show that teachers reveal several difficulties implementing it in the classroom. In fact, research results indicate that the lack of knowledge about STEM education (Ring et al., 2017), the difficulties with scientific concepts and the unwillingness to use strategies different from the traditional ones (Bell, 2016; Herro \& Quigley, 2017) are obstacles to the implementation of STEM education in the classroom. To achieve this, teachers need to expand their professional knowledge and, more specifically, their subject matter knowledge (SMK). In this way, since initial training, it is important to create conditions to engage preservice teachers in STEM experiences that encourage the development of their SMK, which is fundamental for the development of their pedagogical content knowledge (PCK) (Shulman, 1986). This study aims to contribute to this gap. More specifically, this study examines the effects of STEM activities focused on inquiry-based learning on preservice elementary teachers' SMK about basic sound phenomena and concepts.

\section{THEORETICAL BACKGROUND}

This study draws on Shulman's view of subject matter knowledge (SMK). According to the author, SMK is the dimension of teachers' professional knowledge related to the knowledge of the discipline's body of concepts and processes, and it is a prerequisite for the development of PCK (Shulman, 1986). It is consensual that content knowledge is a crucial factor in the improvement of teaching and learning (Ball et al., 2008; Kind, 2009). However, there is a lack of research on SMK in teacher education. Most of the literature published in the last two decades of the 20th century focused on pedagogical content knowledge (Rollnick \& Mavhunga, 2016).

Kind (2009) supports that science SMK influences teachers' confidence and practices, such as helping preservice teachers to select appropriate instructional strategies. A starting point in teacher education is to ensure that preservice teachers know what they should teach (Rollnick \& Mavhunga, 2016). Besides affecting teaching style (Grossman et al., 2005), insufficient content knowledge also makes teachers not aware of students' misconceptions about science topics (Bektas, 2015). As elementary teachers are usually generalists with no or little science background, according to Anderson and Clark (2012), their way of building their SMK is especially interesting.

The lack of science SMK is more common in elementary teachers because most of them either do not study science beyond the age of 16 
(Heywood, 2007), are poorly prepared in teacher education programmes (Abell, 2008; Diamond et al., 2014; Nowicki et al., 2013) where science contents are spread across different disciplines, or receive lower emphasis on the SMK preparation in terms of level and time allocated (Rollnick \& Mavhunga, 2016). Rice (2005) added that subject matter preparation in science and social studies has not been a priority in elementary teacher education.

Limited science knowledge results in low confidence in teaching science (Appleton 2003, 2006; Harlen, 1997; Harlen \& Holroyd, 1997; Heywood, 2007) and negative attitudes toward science, especially physics (Nilsson \& Van Driel, 2011), which leads many elementary teachers to avoid teaching science (Rice, 2005) and develop more traditional teaching practices, relying on textbooks (Appleton, 2007; Harlen, 1997). Research also shows that teachers' SMK influences their students' achievement outcomes (Diamond et al., 2014). Therefore, there is a "need for prospective elementary teachers to develop rich SMK, including knowledge of the nature of science and norms of scientific work, as part of their university coursework" (Haefner \& ZembalPaul, 2004, p. 1671). Several studies demonstrate the effectiveness of SMK teaching through inquiry-based methods to promote the appropriate science SMK (Appleton, 2008; Diamond et al., 2014; Haefner \& Zembal-Paul, 2004) and positive attitudes towards physics in preservice elementary teachers (e.g., Nilsson \& Van Driel, 2011).

Although there are many studies on different contents of physics, the research on sound is scarce (Küçüközer, 2009). Several researchers (Awad \& Barak, 2018; Bolat \& Sözen, 2009; Gülçiçek et al., 2018; Küçüközer, 2009) pointed out a need to further studies on the topic in every educational level. The study of sound and acoustic phenomena is present in early science education curricula, including topics such as sound vibration and wave, its transmission, velocity, loudness, intensity, and isolation (Sözen \& Bolat, 2011) because it "is closely linked to our sensory perceptions" and "one of the areas of physics that most easily adapts to teaching through practical demonstrations" (Merino, 1998, p. 101). Moreover, the introduction to wave concept contributes significantly to the learning of more complex classical or modern physics concepts (Eshach \& Schwartz, 2006; Hrepic et al., 2010). Likewise, Küçüközer (2009) mention that it "plays a critical role in the in the learning of topics such as mechanicelectromagnetic waves, physical optics and quantum mechanics" (p.1889). Therefore, identifying the misconceptions that hinder students from properly understanding sound phenomena should be addressed in science education research (Eshach \& Schwartz, 2006; Houle \& Barnett, 2008) and teacher 
education (Awad \& Barak, 2018; Bolat \& Sözen, 2009; Gülçiçek et al., 2018; Küçüközer, 2009).

\section{METHODOLOGY}

This research uses qualitative and interpretive methodology (Erickson, 1986), focused on the effects of a STEM approach on preservice elementary teachers' SMK about sound. This study was carried out as a part of a broader research project on the influence of STEM activities on physics' learning and motivation. All research was approved by our institutional ethical review board.

The participants in this study are nine females' preservice teachers (Table 1) studying in a Portuguese higher education institution. Only two participants majored in sciences in high school (E3 and E4). The other preservice teachers have a poor background in physics and mathematics subjects.

\section{Table 1}

Participants age

\begin{tabular}{lcc}
\hline Groups & Students & Age (years) \\
\hline G1 & E1 & 19 \\
& E2 & 19 \\
G2 & E3 & 19 \\
& E4 & 22 \\
& E5 & 19 \\
& E6 & 19 \\
G3 & E7 & 37 \\
& E8 & 19 \\
\hline
\end{tabular}

These preservice teachers were enrolled in the Chemistry and Physics Sciences course in the first year of the degree in basic education. Physics' topics covered in the course were astronomy, sound, and energy. The subject of sound was explored over ten hours (about $20 \%$ of the contact hours of the course) through engaging students in STEM activities. The topic sound was taught during the last part of the semester, in January 2019. Students worked in groups of three (G1 - Group 1), four (G2 - Group 2), and two (G3 - Group 3) (Table 1) 
in the development of six STEM activities (Table 2) that included concepts about sound, such as the production of sound vibration, wave, transmission, velocity, and loudness (Table 2).

\section{Table 2}

List of activities and sound subjects

\begin{tabular}{|c|c|}
\hline Activities & Subjects \\
\hline A1 - Good vibrations & Production of sound \\
\hline A2 - How does sound propagate? & Propagation of sound \\
\hline A3 - What are the attributes of sound? & Attributes of sound \\
\hline $\begin{array}{l}\text { A } 4 \text { - What are the characteristics of sound } \\
\text { waves? }\end{array}$ & Sound waves \\
\hline $\begin{array}{l}\text { A5 - How are sounds detected, and what are the } \\
\text { different types of sound? }\end{array}$ & $\begin{array}{l}\text { Sound detection and } \\
\text { types of sound }\end{array}$ \\
\hline $\begin{array}{l}\text { A6 - How does the direction of propagation of the } \\
\text { reflected sound wave relate to that of the incident } \\
\text { sound wave? }\end{array}$ & $\begin{array}{l}\text { Behaviour of sound } \\
\text { waves }\end{array}$ \\
\hline
\end{tabular}

Activity 1. A1 began by reading a short text that mentions the importance of acoustics in our lives, and we suggested that they visualise a video $^{1}$. The activity included two questions (A1-Q1, A1-Q2). The first one was about how the sound is produced, and the second was about how the sound reaches humans. Next, each of the groups was asked to prepare a practical experiment to investigate how sound is produced, considering a set of materials provided (A1-Q3). Students were quite familiar with establishing control variables in previous experiments throughout the course, so they had predefined height, objects' position, and collision surface. After the experiment, the students shared the results obtained with the whole class (A1-Q4, A1-Q5) and answered a question in which they had to identify the sound source of different musical instruments. In the next task (A1-Q7), students were encouraged to strike a tuning fork and observe. Then they were asked to repeat the procedure, placing the tuning fork into a cup of water. In the last question (A1-Q8), students were asked to define sound frequency.

\footnotetext{
${ }^{1}$ HappyMachineMed (2009, September 9). Vocal cords Animation [Video]. YouTube. https://www.youtube.com/watch?v=fqeXCzgDIoA\&ab channel=HappyMachineMed
} 
Activity 2. The second activity started with a cartoon of a concert on the Moon (Figure 1), followed by the question: What is wrong with the picture? (A2-Q1).

\section{Figure 1}

First part of Activity 2 - How do sound propagates?

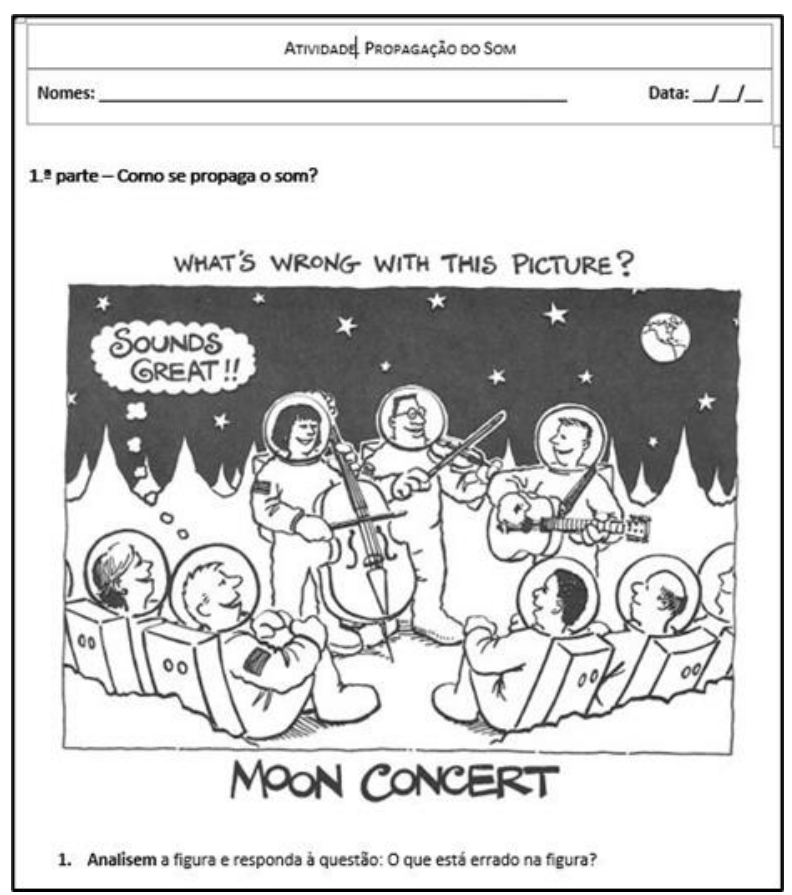

In the second part, students were asked to read a text with situations involving the measurement of the velocity of sound. First, there is an example of the time difference between seeing a lightning bolt and hearing the thunder. Next, students read a description about how the velocity of sound was first estimated by the firing of a cannon. Following the reading, the students were asked to calculate the velocity of sound if a group of people stood 1,700 meters away from a cannon and heard the noise five seconds before they saw the flashlight (A2-Q2). Later, assuming that they heard a thunder ten seconds after watching a lightning bolt, students had to determine how far they were from a thunderstorm (A2-Q3), for that they would have to multiply the velocity in the 
air $\left(340 \mathrm{~m} / \mathrm{s}\right.$ at $15^{\circ} \mathrm{C}$ and normal atmospheric conditions) by the time. Lastly, the PSTs faced the following challenge: Suppose a train is approaching, do we first hear it through the air or if we put our ears on the rail? (A2-Q4).

Activity 3. The third activity combined music and physics and was inspired by the 5E lesson developed by Adams et al. (2014), exploring the attributes of the sound, such as pitch, amplitude, and timbre. The goal was to improve PSTs knowledge about sound waves created by different musical instruments by recognising their similarities and differences (pitch, intensity, and timbre). The activity started with a text about the attributes of sound. Then, to determine what students already knew about the topic, they were asked to draw a string onto a picture with four blank guitars to produce different types of sounds: high, low, loud, soft. After this moment, students planned the construction of a musical instrument using recycled materials, with the purpose to investigate variations in pitch (A3-Q1). They had explored sound produced by string instruments; students had to study the sound produced by wind instruments to solve the following problem: "How does the pitch of the sound produced by an air column vary with its length?" (A3-Q2). The third part of this activity focused on studying: "How does the intensity of the sound produced by a tuning fork vary?" (A3-Q3). Students had to install the app Physics Toolbox Sensor Suite ${ }^{2}$ on a smartphone and use the "Oscilloscope" function. The teacher provided a tuning fork to each group so they could plan their investigation, and a small text explaining that the "Oscilloscope" function would allow them to capture, through the smartphone microphone, the sound produced by a source, converting the sound wave into an electrical signal with the same characteristics. From the generated graph, they could determine the wave period using the horizontal scale of the screen. The teacher also suggested that they explore a computer simulation, "Longitudinal periodic wave $\mid$ spring" (PCCL, 2019), to deepen their knowledge about the graphical representation of a sound wave.

Activity 4. In the fourth activity, students explored several computer simulations representing waves. Firstly, students read a small text and visualised a video ${ }^{4}$ to be acquainted with the content. Next, they explored two

\footnotetext{
${ }^{2}$ Vieyra Software. (2018). Physics Toolbox Sensor Suite (Version 1.9.1) [Mobile application software]. https://play.google.com/store/apps/dev?id=6483394247866966083\&hl=en_US

${ }^{3}$ Physics and Chemistry by Clear Learning (PCCL). (2019). Longitudinal periodic wave | spring [Computer simulation]. http://www.physics-chemistry-interactive-flash-

animation.com/mechanics forces gravitation energy interactive/progressive longitudinal periodic wave spring period length.htm

${ }^{\overline{4}}$ Khan Academy Brasil (2015, September 16). Produção de som [Video]. YouTube. https://www.youtube.com/watch?v= TIjaafWpyk\&ab_channel=KhanAcademyBrasil
} 
PhET simulations, "Wave on a String"5 and "Sound". Once they had done it, students had to answer four questions about what they had experienced (A4Q1). Those questions posed intended to lead students to compare waves with different characteristics, such as transverse waves, longitudinal waves, mechanic waves, and electromagnetic waves. Then, after a moment of sharing and discussing each groups' results with the whole class, the students answered another set of questions about the attributes of the sound (A4-Q2). Finally, all groups embraced (A4-Q3) a new optional challenge proposed, involving the exploration of the "Simple Wave Simulator Interactive" to study whether changes made in the wave frequency and amplitude influenced its propagation velocity.

Activity 5. The fifth STEM activity started with the visualisation of two videos ${ }^{8}$. Students were asked to explain how the sound reach human ears, how the sound is detected by humans' ears and the causes for hearing loss (A5Q1). The second part (A5-Q2) fell under the subtopic types of sounds and started with the viewing of two videos, one with a hearing test ${ }^{9}$, and another with a human audio spectrum ${ }^{10}$. After becoming more familiar with hearing tests and hearing ability at different frequencies, students explored an audiogram ${ }^{11}$. Next, they had to identify the types of sounds that humans cannot hear. Students also had to search the hearing range of different animals and compare it with humans. After that, each group had to make their own audiogram using a free hearing test available online ${ }^{12}$. Then, they had to compare it with the one they had analysed previously. The following task consisted of analysing and describing the hearing ability of two individuals. The results for the right ear are marked with a red "O", and the results for the left ear are marked with a blue "X". The third part of the activity (A5-Q3)

\footnotetext{
${ }^{5} \mathrm{PhET}$ Interactive Simulations. (n.d.). Wave on a String (Version 1.1.22) [Computer simulation]. https://phet.colorado.edu/pt/simulation/wave-on-a-string

${ }^{6}$ PhET Interactive Simulations. (n.d.). Sound (Version 2.19) [Computer simulation]. https://phet.colorado.edu/en/simulation/legacy/sound

${ }^{7}$ The Physics Classroom. (n.d.). Simple Wave Simulator Interactive [Computer simulation]. https://www.physicsclassroom.com/Physics-Interactives/Waves-and-Sound/Simple-Wave-Simulator

${ }^{8}$ AsapSCIENCE. (2013, August 13). How Old Are Your Ears? (Hearing Test). [Video]. YouTube. https://www.youtube.com/watch?v=VxcbppCX6Rk\&ab channel=AsapSCIENCE

${ }^{9}$ ScienceForum. (2011, October 2). Cool Hearing test [Video]. YouTube. https://www.youtube.com/watch?v=h514Rt4O17M\&ab channel=ScienceForum

${ }^{10}$ Adminofthissite. (2012, January 2018). 20Hz to $20 \mathrm{kHz}$ (Human Audio Spectrum). [Video]. YouTube. https:/www.youtube.com/watch?v=qNf9nzvnd1k\&ab channel=adminofthissite

${ }^{11}$ Adapted from Nishida, S., Weber, S., Oliveira, F., \& Troll, J. (n.d.). Como ouvimos o mundo? Saúde da Audição.

https://www2.ibb.unesp.br/Museu_Escola/2_qualidade_vida_humana/Museu2 qualidade_corpo_sensorial audicao2.htm

${ }^{12}$ Miracle-Ear. (2020). Free Online Hearing Test. https://www.miracle-ear.com/online-hearing-test
} 
consisted of a class project to study sound pollution levels at a school. For its implementation, each group was responsible for measuring the sound intensity in a school area with a sonometer, collecting data at different times of the day.

Activity 6. This activity started with a brief introduction to sound wave reflection, which presented the following problem: "How does the direction of propagation of the reflected sound wave relate to that of the incident sound wave?". To solve the problem, students developed an investigation (A6-Q2). Students found out that with a 45-degree angle between the tubes they were able to distinguish the reflected sound of an alarm clock (produced by the smartphone) and that some materials absorbed more sound than others (A6-Q2). The investigation allowed students to understand what happens to sound when it strikes different surfaces and compared different materials regarding their ability to reflect and absorb sound (A6-Q3). After this experiment, students were challenged to develop another investigation to identify other sound behaviours that occur simultaneously with reflection (A6-Q4). Next, PSTs had to read a small introduction about echo and indicate the conditions for this phenomenon to occur (A6-Q5) on their worksheets. The sixth task referred to reverberation. After reading a brief introduction to this phenomenon, students had to answer the following question: "Reverberation can make it easier to hear a speaker in an auditorium, but if it is excessive, the sound quality would be highly affected. How can this phenomenon be mitigated when it is undesirable?" (A6-Q6). The next task began with an introduction to echolocation, a phenomenon used by several animals. After that, students were asked to give one example of an instrument inspired by this acoustic phenomenon and to explain how it works (A6-Q7). After a moment of sharing and discussing each group answers with the whole class, the students read a small introduction to the subject and searched on YouTube for some actual examples of the Doppler effect, describing afterwards what they heard (A6-Q8). Then, they used a computer simulation ${ }^{13}$ to engage with that topic. After that, they had to select possible scenarios in which the Doppler Effect would occur from a list in their worksheets (A6-Q9).

Data Collection and analysis. Two data collection methods were used: (i) students' productions developed through six STEM activities; (ii) field notes collected by the first author of this article during the classroom observation. We used an inductive strategy of content analysis, recurrently examining the data to uncover salient patterns and themes associated with the research aims (Miles

\footnotetext{
${ }^{13}$ Fendt, W. (1998). An Example of Doppler Effect. [Computer simulation]. https://www.walterfendt.de/htm15/phen/dopplereffect en.htm
} 
\& Huberman, 1994). All documents were read, and the targeted text was segmented. Each segment was assigned a code according to the explicit SMK (correct, incorrect, and incomplete).

\section{RESULTS AND ANALYSIS}

The study results are presented according to the subject of the sound focused in each STEM activity developed.

Sound production (Activity 1). After viewing two videos about sound production, both groups considered that sound is produced by vibrating objects (A1-Q1). However, when asked about the sound production in humans, only G1 did not refer to the vibration of the vocal cords (A1-Q2).

Students planned an experiment (A1-Q3) to solve a problem: "How are sounds produced?" To guide their investigation and encourage them to hypothesise, the teacher provided several objects and asked questions like: "How do you think dropping different objects from the lab table might affect the noise you hear?". PSTs dropped different materials (pencil, paperclip, piece of wood, coin, Styrofoam, plastic bottle cap, paper ball, and cleaning cloth) and heard the sound they made, associating the contact of the object with the lab tables with the noise produced. However, students' answers (A1-Q3) did not clarify whether they had perceived the difference in materials' hardness by the level or volume of sounds being produced. Other observations were not included in their registers, for instance, they saw the coin vibrating until it stopped, which reinforced the idea of vibration of the sound source as the cause of sound production.

G1 and G2 noted that the intensity of the sound produced depended on the type of material (A1-Q4), and, during the experiment, they argued that heavier objects make a louder sound because they hit the lab table more strongly. However, their conclusions did not include the discussion regarding the effect of objects' properties on sound production. G3 was the only group that referred to the proprieties of the materials, stating that "the coin produced a louder sound probably because it is a denser material, unlike the Styrofoam, which produces less noise because it is less dense" (A1-Q4, G3). This sentence revealed some erroneous ideas about the effect of density of materials in sound transmitting. The metals are indeed denser than Styrofoam; however, the reason the coin produces a louder sound is related to the fact that it is a more rigid material that vigorously vibrates, while Styrofoam is more flexible and absorbs the sound. 
In the first activity, the students defined the investigation to be carried out to solve the problem. Although the purpose was to explore sound transmission, students freely explored other aspects such as sound loudness. Having been implemented at the beginning of the sound content approach, the concepts involved had not yet been explored, which may have generated some misinterpretations that were clarified in later activities.

After completing the experiment they planned, G2 concluded (A1-Q5) that the production results from the vibration of two bodies (the one that is thrown and the surface where the first one collides). G1 stated that the "sound is produced through the vibration between two bodies" (A1-Q5, G1). This sentence is quite dubious concerning students' conceptions about sound production. For instance, it is unclear if they explain sound production based on the vibration of the sound source as a consequence of action. Another ambiguous conclusion was noticed on the G3 datasheet, which said: "the sounds are obtained due to the vibration that occurs when the object hits the surface. This vibration propagates through the air (through the oscillation of air particles) reaching us in the form of a sound" (A1-Q5, G3).

When students were asked to identify sources of sound in music instruments (A1-Q6), G1 and G2 failed to identify the source correctly in a flute and a saxophone. This evidence points out PSTs difficulties in applying the concepts previously explored to a different context, such as identifying the vibration of the air inside the column in those instruments as the sound source. For them, it was easy to point out solid materials and strings as the source of sound in drums, a piano, and a cello. Students revealed that their conceptions about sound production (vibration of the sound source) depend on the context.

Regarding the task that involved the percussion of a tuning fork (A1Q7), G1 stated they "hear the sound propagated through sound waves. In this process, air corpuscles move close to each other and move away successively. When we put the tuning fork in a cup of water, we watch sound waves, and we cannot hear any sound" (A1-Q7, G1). On the other hand, G2 stated that "air corpuscles vibrate and transfer energy to each other" (A1-Q7, G2) and the same can be observed in the water. Even PSTs did not explicitly refer to the vibrations of the tuning fork as responsible for the noise. The students discussed that aspect with each other in class. All groups recognised that sounds travel through the air, but G1 did not use the term "vibrations" to explain how sounds are produced in their notes. Two groups described the sound propagation at the microscopic level. For example, G2 stated that the movement of particles within the medium is vibrational, and there is energy transfer between particles, 
and G1 referred to compression and rarefaction regions. Nevertheless, the last group made some confusing statements about sound propagation that left some doubts about whether students hold a materialistic view of the sound.

All groups correctly answered the last question (A1-Q8), though G2 included that hertz is the unit of frequency in the International System of Units (SI).

Sound propagation (Activity 2). The PSTs considered it would be impossible to hear a concert on the Moon because "sound waves need a medium to propagate" (A2-Q1, G2). G1 presented a more confusing explanation revealing the misconception that the Moon has no gravity, however they make it clear that "because there's no particles in the environment, sound waves can't be transmitted" (A2-Q1, G1). According to both groups, sound cannot travel through a vacuum, while G3 did not mention it.

In the second part, all groups correctly determined the velocity dividing distance by time (A2-Q2). Next, students had to determine how far they were from a thunderstorm (A2-Q3), and again, all answers were correct. Nevertheless, G3 did not write the mathematical equation for the velocity in their worksheet.

Lastly, after some group discussion, they came to the correct answer: we ear the train first on the rail (A2-Q4). During the class discussion, we noted that for some, the fact that the velocity of sound is slower than it is in solids was not intuitive. Although the teacher recommended that they use their knowledge about the constitution of matter to explain their conclusions, all groups stated that since the density of the solids is higher, propagation velocity is faster. There is an obvious confusion between the elastic properties of the material and its density. The first refers to the forces of attraction between atoms and/or molecules that determine the speed of vibration, and the second describes the mass of a substance per volume, which can reduce the speed of sound if the molecules are larger. Students' difficulties in this topic could have been minimised with the previous exploration of the Newton-Laplace formula $(v=\sqrt{K} / \mathrm{d}$, where $K$ is a coefficient of stiffness and $\rho$ is the density).

Sound attributes (Activity 3). In the third STEM activity, students' drawings revealed they have some knowledge about the musical instrument (guitar) and the sound it produces. For instance, G1 and G2 positioned the strings correctly to produce a high and low sound, associating the first to a thinner string. and the former to a thicker one. When asked to plan the design of a musical instrument to investigate variations in pitch (A3-Q1), all groups 
listed the materials and procedures to develop their own guitar. G2 and G3 were more accurate, stressing the need to use two string types (thin and thick). G2 presented a better answer about intensity, referring that a louder sound results from pulling a string more vigorously. About the procedures, these students also stood out, mentioning that a looser and a stretched string would be applied in the instrument. The instruments created by each of the groups were similar, probably because they worked very close. However, G1 needed more guidance from the teacher. As for the recording of observations, G2 stood out by analysing two factors that determine the pitch of a string, i.e. the thickness and length of the strings. Instead, G1 and G3 did not include this last aspect in their investigation. Therefore, it is not surprising that their conclusions were not complete. On the other hand, G3 referred to the tension of the string. In addition, G3 notes revealed the wrong association between sound intensity and sound pitch. That was quite evident on their registers: "we verified that a less stretched string (...) produces a weaker sound than a stretched string" (A3-Q1, G3).

Next, students had to investigate the sound produced by wind instruments (A3-Q2). Therefore, they drew up a plan that included placing three different amounts of water in bottles. G1 and G2 experiments consisted of blowing air across the tops of the three Erlenmeyer flasks containing different amounts of water. G3 experiment was similar, but they used sand instead of water. On their records, the PSTs registered that they could alter the pitch of their flasks by putting water/sand in them since the water/sand changes the length of the air columns in the flasks, specifically a small column of air produces a high-pitch sound. Despite accurate on their findings, conclusions were not fully completed because they did not mention that adding water/sand decreases the amount of air space, which means there is less air to vibrate, and vibrations are faster and produce a higher pitch. Additionally, if they had tapped the flasks with a spoon, for example, findings would be quite the opposite. That happens because when we tap a bottle, we are making the glass vibrate, not the air.

The third part of this activity explored variations in sound intensity produced by a tuning fork (A3-Q3). G2 stood out, presenting in detail the procedure to be carried out in its investigation, while the remaining groups presented incomplete descriptions and several scientific inaccuracies. For instance, G1 said they would "strike the tuning fork strongly and then lightly to observe the difference in wave frequency" (A3-Q3, G1) but instead, the goal was to study the sound amplitude. This apparent confusion is also evident in their registers after the experiment in which they mentioned the high height of the wave when they hit hard the fork, although they state correctly on their 
conclusions the relation between sound intensity and the force. G3 presented a poor description of the procedures but correctly concluded that sound was more intense when they applied a higher force on the fork. Although conclusions showed all groups understood the relation between sound intensity and the strike applied on the tuning fork, it was never mentioned the term "amplitude" for the loudness of the sound or the "height of the wave from the resting position" (A3-Q3, G2).

Sound waves (Activity 4). Regarding the first simulation explored in the fourth activity, all groups agreed that waves transfer energy but not matter (only oscillation of matter). About the second simulation, groups concluded that the compression of the wave increases if they increase the sound amplitude. We noticed differences between the groups when they had to identify the type of waves (mechanical or electromagnetic) of each simulator. G1 answered that both waves are mechanical because it requires a medium to transfer energy. The other groups stated, incorrectly, that waves represented in the second simulation are electromagnetic. All groups correctly identified the simulator that presented a type of wave in which the direction of propagation coincides with the direction of vibration.

Following this introduction to the topic, students had to answer four questions. Question 1 presented a picture of a wave on a string from the simulation and asked what would happen to that wave if the frequency increases. G1 answer was a bit vague: "If we increase the frequency, the wave increases its oscillation producing a high-pitched sound" (A4-Q1, G1). The other groups mentioned what the wave would look like more precisely: "the wave would be more compressed, and there will be more vibrations in the same time interval" (A4-Q1, G2). G3 did not allude to the number of vibrations per unit of time, however, they made a drawing of what the wave would look like. None of the groups mentioned the wavelength. The second question focused on what would happen to the wave if the amplitude increased. Again, G1 answer was incomplete, they simply stated that "the wave will increase in height" (A4-Q2, G1). The other groups had provided more complete answers, e.g." "the distance from the equilibrium position to the end of the wave increases" (A4-Q2, G3). In the third question, all groups correctly identified the figure that represented a high-pitch sound. G1 and G3 justified their choice by referring to a higher frequency, and G2 was more precise, mentioning the number of vibrations per unit of time, just as they had done in the first question. Question 4 was intended to lead students to identify the image (taken from the second simulator) that would illustrate an individual hearing a high-pitch sound. G1 failed to identify correctly the image representing a high-pitch sound; instead, they chose an 
image representing a loud sound. Again, these students revealed some confusion between "sound intensity" and "sound pitch level". The other groups identified correctly, but G3 did not give a justification as complete as that of G2, quite like question 3. Concerning the extra task, only G2 answered incorrectly that wave frequency and amplitude affect wave velocity.

Sound detection and types of sound (Activity 5). The students' answers revealed more mature ideas about sound in the fifth activity, especially if we compare to those presented in the first activity. For instance, they no longer described the sound as vibration and/or an entity different from the medium, and described that "The sound reaches our ears through vibrations because the sound is a mechanical wave that compresses and decompresses, through the air" (A5-Q1, G1) and "reaches our ears through the oscillation of particles caused by sound waves" (A5-Q1, G3). About the sound detection process by the human being, G2 stood out with a very detailed description in their worksheet according to what they observed in the video. All groups presented the main causes of hearing loss in question 3.

In the second part of this activity (A5-Q2), all groups indicated infra and ultrasound, but only G2 and G3 mentioned sound below $20 \mathrm{~Hz}$ and above $20000 \mathrm{~Hz}$ as impossible for humans to hear. They were all able to identify several animals with more sensitive hearing than humans, such as whales, elephants, and spiders, which can hear infrasound; or dolphins, bats, and dogs, which can hear ultrasound. G1 even mentioned that some animals are sensitive to infrasonic frequencies generated by earthquakes or volcanic eruptions, which can explain why they behave unusually before those natural disasters occur. Students' notes showed some difficulties in interpreting information from graphs in all groups, probably because the generated audiogram has the y-axis reversed, i.e., the y-axis grows from top to bottom. Also, they struggled to understand that two different factors that affect hearing: range of audible frequencies and minimum intensity at each frequency within that range. Only G3 distinguished the two factors when comparing the audiograms, G2 compared maxim and minimum levels of sound intensity, not considering the different frequencies, and G1 only referred to the range of audible frequencies. The following task comprised the analysis of the hearing ability of two individuals. G1 did not present their answer in the worksheet and, confronted by the teacher, they explained they did not realise they needed to write a description. Thus, it is not possible to assess whether they really understood the task. G3 correctly identified the individual with a moderate degree of hearing loss in one ear. Instead, G1 failed to comprehend that normal hearing ability is reflected by a range of hearing level near 0 decibels $(\mathrm{dB})$, which became quite 
clear in the following statement: "the individual B hears within a range of 56 $\mathrm{dB}$ (left ear) to $-2 \mathrm{~dB}$ (right ear) (...) presenting a normal hearing ability". Next, students were asked why humans cannot hear every sound. G2 and G3 were able to identify the two factors involved - sound intensity and frequency, but G1 only referred to the second one.

Noise measurements at different locations in the school (A5-Q3) showed that some crowded places, especially the cafeteria at lunchtime, presented high levels of noise. But in general, students registered sound levels below $80 \mathrm{~dB}$, which G1 interpreted as a high level of noise pollution, unlike the other groups. The PSTs failed to substantiate their analysis of the data collected. They could have used the recommendations of the World Health Organization (WHO) to support their conclusions, which defines noise above $65 \mathrm{~dB}$ and states that noise becomes harmful when it exceeds $75 \mathrm{~dB}$.

The behaviour of sound waves (Activity 6). To investigate how the direction of propagation of the reflected sound wave relates to that of the incident sound wave (A6-Q1), all groups used a smartphone as a sound source and established the research variables. With some help from the teacher, groups developed their investigation plan that consists of producing a sound through a card tube against a wall made of different materials (cardboard paper, Styrofoam, thin plastic, thick plastic, mirror). G3 draw a representation of the experiment (Figure 2).

\section{Figure 2}

G3's representation of the experiment

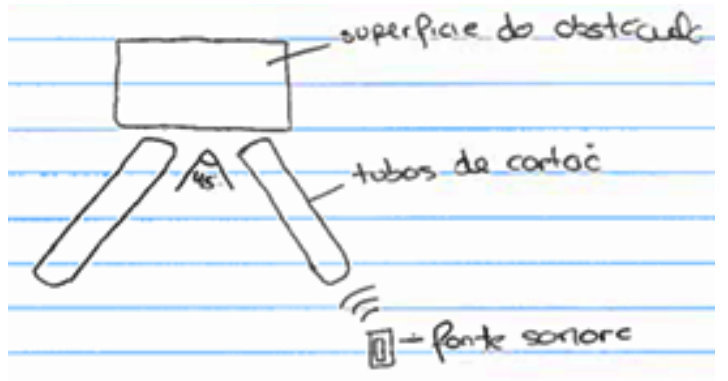

The data collected by all groups were in line with the idea that reflection will be more significant if the surfaces where the sound wave strikes are hard and polished and less significant if their surfaces are soft and fuzzy 
(A6-Q2). The groups presented similar conclusions; they all answered the same way to the initial problem: "When a sound encounters an obstacle, it can change its direction of propagation, but it continues to propagate in the same medium. The first sound is called incident and the second sound is reflected" (A6-Q3, G3). All groups failed to go further in their conclusions and did not mention that the directions between incident sound waves and reflected sound waves make equal angles with the normal to the reflecting surface.

Then PSTs had to develop another investigation to identify other sound behaviours that occur simultaneously with reflection (A6-Q4). G1 and G3 opted to plan an investigation quite similar to the previous one to study absorption, which did not bring new knowledge beyond confirming what had already been observed in the first experiment. G2, on the other hand, decided to carry out a simple experiment that demonstrated the refraction of sound, involving the passage of sound waves from one room to another through a glass door and a concrete wall.

Regarding echo (A6-Q5), G1 and G3 stated that: "For it to occur, it is not enough to have an obstacle, the sound must travel a distance of $17 \mathrm{~m}$ in each direction, that is, the obstacle must be at least 17 meters away from the person so that the person can hear it" (A6-Q5, G1). G2 gave a mathematical explanation of this acoustic phenomenon, taking into account the human ability to distinguish echo from the original sound if the delay is less than $0.1 \mathrm{~s}$ and the velocity of sound in dry air at a temperature of $25^{\circ} \mathrm{C}$ (approximately $343 \mathrm{~m} / \mathrm{s}$ ).

About reverberation (A6-Q6), all groups agreed that adequate materials would be needed, for example, G1 stated that rough walls increase sound absorption. G2 suggested "cork, because it is a polished and rigid material" (A6-6, G1), which is strange because its characteristics are quite the opposite of those described. G3 did not give any example of materials to cover the walls and the roof of the auditorium.

In the next task, students were asked about echolocation. G1 selected the ultrasound, and G2 and G3 opted for the sonar, and all were able to explain the basics of the way these instruments word.

The last part of the activity focused on the Doppler effect. Students' sound perceptions were quite different, although they watched the same videos. For instance, G1 considered that: "The sound, when we hear it from the front, is different from the sound we hear when the car has passed us, that is, when the car comes in our direction, we hear a high-pitched sound and when the car has passed we hear a lower sound" (A6-Q8, G1). G3 students describe the 
situation slightly differently but considering the same principles: "the sound produced by the car's horn is high before the car passes by the observer, then becomes low as the car moves away from the observer" (A6-Q8, G3). G2 remarks are quite different: "The sound of the horn, when the car was far away, gave the impression of being low. As the car approached and when in it stands in front of the observer, the sound was increasingly high" (A6-Q8, G2). This last statement revealed the wrong belief that the Doppler effect is related to the distance between the source and the observer.

In the last task (A6-Q9), G1 chose an incorrect option: "A sound source and an observer who is not on the move (like a person watching television sitting on a couch)". The other groups selected the two correct answers: "A moving sound source (like an aeroplane passing over our head)"; "A moving observer (like a person going through a loud sound)". These students showed some issues in knowledge appropriation about the Doppler effect.

Table 3 synthesises the main conceptions revealed by the PSTs concerning the subjects of sound focused on STEM activities that were carried out.

\section{Table 3}

Students'answers relate to sound subjects

\begin{tabular}{|c|c|c|}
\hline Subjects & Explanations & Groups \\
\hline $\begin{array}{l}\text { Production of } \\
\text { sound }\end{array}$ & $\begin{array}{l}\text { - vibration of the sound source as a result } \\
\text { of an action } \\
\text { - vibration propagates through the air } \\
\text { - vibration of the sound source varies by } \\
\text { the context }\end{array}$ & $\begin{array}{l}\text { G1, G2 and } \\
\text { G3 } \\
\text { G3 } \\
\text { G1 and G2 }\end{array}$ \\
\hline $\begin{array}{l}\text { Propagation } \\
\text { of sound }\end{array}$ & $\begin{array}{l}\text { - } \quad \text { sound propagation requires a medium } \\
\text { - } \text { sound is fast in solid, as it is denser }\end{array}$ & $\begin{array}{lll}\text { G1, } & \text { G2 } & \text { and } \\
\text { G3 } & \\
\text { G1, } & \text { G2 } & \text { and } \\
\text { G3 } & & \end{array}$ \\
\hline $\begin{array}{l}\text { Attributes of } \\
\text { sound }\end{array}$ & $\begin{array}{l}\text { - factors that determine the pitch of a } \\
\text { string (length and diameter) } \\
\text { (Length and tension) } \\
\text { - in wind instruments, a higher pitch is } \\
\text { related to a small column of air }\end{array}$ & $\begin{array}{l}\text { G2 } \\
\text { G3 } \\
\text { G1, G2 and } \\
\text { G3 }\end{array}$ \\
\hline
\end{tabular}




\begin{tabular}{|c|c|c|}
\hline & 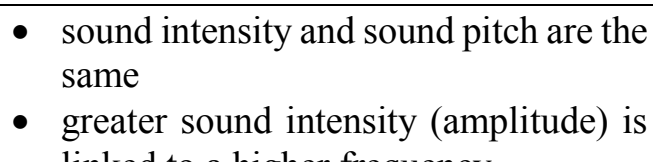 & G3 \\
\hline Sound waves & $\begin{array}{l}\text { - confuse frequency with amplitude } \\
\text { - velocity of sound is dependent on } \\
\text { frequency and amplitude }\end{array}$ & $\begin{array}{l}\text { G1 } \\
\text { G1 and G3 }\end{array}$ \\
\hline $\begin{array}{l}\text { Sound } \\
\text { detection and } \\
\text { types of sound }\end{array}$ & $\begin{array}{l}\text { - reaches our ears through vibrations } \\
\text { because the sound is a mechanical } \\
\text { wave }\end{array}$ & G1 \\
\hline & $\begin{array}{l}\text { - reaches our ears through the } \\
\text { oscillation of particles caused by } \\
\text { sound waves }\end{array}$ & G3 \\
\hline $\begin{array}{l}\text { Behaviour of } \\
\text { sound waves }\end{array}$ & $\begin{array}{l}\text { - Doppler effect is directly connected to } \\
\text { distance between source and observer }\end{array}$ & G2 \\
\hline
\end{tabular}

\section{DISCUSSION}

In this section, we discuss the study results related to the effects of a STEM approach on preservice teachers' SMK, based on the literature reviewed earlier in this work.

Sound production. Students' answers point to an explanation of sound production caused by the vibration of the sound source. Although during class the PSTs discussed aspects about sound production as a phenomenon based on action or physical properties of the source, such as the study developed by Küçüközer (2009), that fact was not explicit in their answers. G3 revealed an interpretation of the sound as an entity. Houle and Barnett (2008) referred to this as "sound is the vibration" misconception and Hrepic et al. (2002) described it as a shaking model. According to the mentioned authors, students who hold this view considers the sound as an entity different from the medium through which it propagates. Results revealed other similarities with those obtained by Küçüközer (2009): that the explanation provided by the PSTs "linking sound production to the vibration of the sound source varies by the context" (p. 1890). We noticed that G1 make some confusing remarks about sound propagation, which make us believe they could hold a materialistic view of sound as a "material or substance" (Houle \& Barnett, 2008, p. 247), an "entity carried and transmitted by the molecules of the medium" (Küçüközer, 2009, p. 1891). According to a review of literature developed by Houle and Barnett (2008), this is one of the two most significant misconceptions regarding 
sound: "Students view sound as a substance with the physical properties of matter rather than as a process of energy transmission through a substance" (p. 244).

Sound propagation. The PSTs could describe the sound propagation correctly at the microscopic level, revealing that they were aware of the need for a material medium. These findings are quite different from those obtained by Küçüközer (2009) in that only $30 \%$ of the PSTs mentioned that a medium is required for the sound propagation. All groups gave incorrect explanations for why sound is faster in solids, associating the velocity of the sound with the density of the material. In Bolat and Sözen (2009) study, the PSTs also revealed this misconception that sound is fast in solid because it is denser. However, in that research, most of the correct explanations presented by the PSTs referred to the fact that molecules are closer in a solid. Like Linder (1993), these conceptualisations of the factors affecting the speed of sound and the confidence students exhibited when giving their explanations revealed that their understandings were left unchallenged. As described in the Results section, the misunderstanding that the density of the medium is not the main factor for the speed of sound could have been overcome through the Newton-Laplace equation, an aspect that was not considered in the studies mentioned above, but that will be considered in the future if this activity is to be performed again.

Sound attributes. During the third STEM activity (design of string and wind instruments), students also demonstrated some difficulties to identify the factors that affect pitch in a string and to conclude that the pitch generated by air blown across the top end of a bottle will be higher when it contains a greater volume of water, which is quite similar to some results obtained by Barniol and Zavala (2017). When engaged in the design of a string instrument, one group of students (G3) failed to distinguish the concept of sound from the concept of sound intensity (volume), which is in line with the work of Özkan and Selçuk (2013), whose findings demonstrated that most students considered that those concepts were the same. The research developed by Pejuan et al. (2012) likewise confirmed that many college students linked these two parameters. Still about the attributes of the sound, but now during the hands-on task with a tuning fork, another group (G1) revealed the same misconceptions linking higher pitch (frequency) with greater sound intensity (amplitude), similar to findings obtained by Pejuan et al. (2012).

Sound waves. The analysis of the fourth activity worksheets on the topic of sound waves also showed G1 misunderstanding about the previous parameters (amplitude and frequency) mentioned before, which is one of most 
common errors concerning sound variables (Barniol \& Zavala, 2017). Some PSTs (G1 and G3) considered that the velocity of sound dependende on frequency and amplitude. In this regard, Barniol and Zavala (2017) found that the belief that the rate of sound waves depends on frequency is related to the inappropriate use of the equation $v=f \lambda$. Students did not realise that the frequency depends on the source not on the medium (like velocity). A previous study (Pejuan et al., 2012) also showed that a significant number of participants attributed a higher sound velocity to a higher frequency and a greater sound intensity. According to those authors, this is based on reasoning that suggests object-like properties of sound.

Sound detection and types of sound. Previous activities may have had an impact in changing some erroneous ideas about the nature of sound, because the results show that teachers move away from the belief that sound is a vibration and/or an entity different from the medium (Houle \& Barnett, 2008; Hrepic et al., 2002).

Behaviour of sound waves. Overall, the PSTs made correct assumptions about reflection, refraction, absorption, and other phenomena. They were even able to point out several limitations of the performed experiments, for instance, smartphones do not produce sounds with constant frequency or intensity and using our ear as a detector of sound intensity is not recommended because sound perception is relative (Saraiva, 2013). Contrary to Bolat and Sözen (2009) findings, the PSTs who participated in the current study could correctly identify materials used to isolate the sound. Addressing the Doppler effect, on the contrary, exposed scientific inconsistencies. Notably, a common misconception that is stated by Viennot and Leroy (2004), is that "the Doppler effect is directly connected to the distance between source and the observer, whereas the connection is actually quite indirect" (p. 275). The Doppler effect is an apparent shift in the observed frequency of a sound wave due to the relative motion of the source and of the observer. What really increases is the sound intensity, which often leads to these inconsistencies, as mentioned by Mosabala (2014), who obtained similar results. Neuhoff and McBeath (1997) called it the "Doppler illusion" and explained that the main cause of these misunderstandings about the Doppler effect is related to the often-confused distinction between frequency (that is actually decreasing as the source approaches the observer) and perceptual pitch. 


\section{CONCLUSIONS}

This study describes the implementation of a STEM approach focused on sound concepts with preservice elementary teachers. STEM activities rely on inquiry-based learning, hands-on experiments, and the use of a wide range of ICT resources, such as interactive simulations and videos. Teaching methods, along with the ICT resources, contributed to motivating the PSTs and tackling their difficulties and scientific inconsistencies identified throughout the study (Awad \& Barak, 2018). In this study, the PSTs revealed many misconceptions about sound, which overlaps with previous studies (Awad \& Barak, 2018; Barniol \& Zavala, 2017). This fact emphasises the need to develop activities that promote conceptual change in teacher training. The fact that these PSTs were not familiar with STEM activities or with an inquiry approach may have contributed, according to Awad and Barak (2018), to the difficulties they had. Therefore, these authors suggest starting with more closed activities and opening progressively throughout the programme.

Remarkably, the study results pointed to the evolution of the PSTs' SMK. We also found that they overcame some alternative ideas about sound concepts. These results demonstrated that the STEM approach favoured an active involvement of the PSTs in their learning, connecting contents to reallife situations. For instance, the PSTs need to learn how to integrate science and music with mathematics and literacy goals (Adams et al., 2014). STEM activities also had a positive effect on PSTs' SMK, which is consistent with the results obtained from Awad and Barak's (2018) study. Therefore, we recommend the STEM approach to address complex physics topics, specifically in teacher education, to prepare better primary teachers, who usually have a poor background in science, to teach STEM and motivate their future students to pursue careers in STEM. As for the topic of sound, due to the rooted inaccurate scientific mental models that emerged, it is essential that inservice teachers engage in professional development. There is also a need for further studies on the impacts of a STEM approach in PSTs' PCK. In this sense, we intend to continue the research, but now focusing on PCK development through planning STEM activities about sound.

\section{AUTHORS' CONTRIBUTIONS STATEMENTS}

$\mathrm{MB}$ and $\mathrm{MC}$ conceived the presented idea. MB and MC developed the theory. MC adapted the methodology to this context, created the models, performed the activities, and collected the data. MC analysed the data. All 
authors actively participated in the discussion of the results, reviewed, and approved the final version of the work.

\section{ACKNOWLEDGEMENTS}

This work is supported by national funds through the FCT - Portuguese Foundation for Science and Technology, I.P., under the project number PTDC/CED-EDG/31480/2017.

\section{DATA AVAILABILITY STATEMENT}

The data supporting the results of this study will be made available by the authors upon reasonable request.

\section{REFERENCES}

Adams, K. L., Pedersen, J., \& Narboni, N. (2014, February). Do you hear what I hear? A 5E lesson combines music, science, and students' backgrounds. Science and Children, 1(1), 56-63.

Anderson, D., \& Clark, M. (2012). Development of syntactic subject matter knowledge and pedagogical content knowledge for science by a generalist elementary teacher. Teachers and Teaching: Theory and Practice, 18(3), 315-330.

http://doi.org/10.1080/13540602.2012.629838

Appleton, K. (2003). How do beginning elementary school teachers cope with science? Toward an understanding of science teaching practice.

Research in Science Education, 33, 1-25. https://doi.org/10.1023/A:1023666618800

Appleton, K. (2006). Science pedagogical content knowledge and elementary school teachers. In K. Appleton (Ed.), Elementary science teacher education: International perspectives on contemporary issues and practice (pp. 31-54). Association for Science Teachers and Laurence Erlbaum.

Appleton, K. (2007). Elementary science teaching. In S. K. Abell, \& N. G. Lederman (Eds.), Handbook of research on science education (pp. 493-536). Lawrence Erlbaum. 
Appleton, K. (2008). Developing science pedagogical content knowledge through mentoring elementary teachers. Journal of Science Teacher Education, 19(6), 523-545. https://doi.org/10.1007/s10972-008-9109$\underline{4}$

Awad, N., \& Barak, M. (2018). Pre-service Science Teachers Learn a Science, Technology, Engineering and Mathematics (STEM)Oriented Program: The Case of Sound, Waves and Communication Systems. Eurasia Journal of Mathematics, Science and Technology Education, 14(4), 1431-1451. https://doi.org/10.29333/ejmste/83680

Ball, D. L., Thames, M. H., \& Phelps, G. (2008). Content knowledge for teaching: What makes it special? Journal of Teacher Education, 59, 389-407. https://doi.org/10.1177/0022487108324554

Barniol, P., \& Zavala, G. (2017). The Mechanical Waves Conceptual Survey: An Analysis of University Students' Performance, and Recommendations for Instruction. EURASIA Journal of Mathematics Science and Technology Education, 13(3), 929-952. https://doi.org/10.12973/eurasia.2017.00651a

Bektas, O. (2015). Pre-Service Science Teachers' Pedagogical Content Knowledge in the Physics, Chemistry, and Biology Topics. European Journal of Physics Education, 6(2), 41-53.

Bell, D. (2016). The reality of STEM education, design, and technology teachers' perceptions: a phenomenographic study. International Journal of Design Education, 26, 61-79. https://doi.org/10.1007/s10798-015-9300-9

Bolat, M., \& Sözen, M. (2009). Knowledge levels of prospective science and physics teachers on basic concepts on sound (sample of Samsun city). Procedia Social and Behavioral Science, 1(1), 1231-1238. https://doi.org/10.1016/j.sbspro.2009.01.220

Chittum, J. R., Brett, D. J., Akalin, S., \& Schram, A. B. (2017). The Effects of an Afterschool STEM Program on Students' Motivation and Engagement. International Journal of STEM Education, 4(1), Article 11. https://doi.org/10.1186/s40594-017-0065-4

Chiu, M.- H., \& Duit, R. (2011), Globalisation: Science education from an international perspective. Journal of Research in Science Teaching, 48(6), 553-566. https://doi.org/10.1002/tea.20427 
Christensen, R., \& Knezek, G. (2017). Relationship of middle school student STEM interest to career intent. Journal of Education in Science, Environment and Health (JESEH), 3(1), 1-13. https://doi.org/10.21891/jeseh.275649

Crippen, K. J., \& Antonenko, P. D. (2018) Designing for Collaborative Problem Solving in STEM Cyberlearning. In Y. Dori, Z. Mevarech, \& D. Baker (Eds.) Cognition, Metacognition, and Culture in STEM Education. Innovations in Science Education and Technology (pp.89116). Springer. https://doi.org/10.1007/978-3-319-66659-4

Diamond, B. S., Maerten-Rivera, J., Rohrer, R. E., \& Lee, O. (2014). Effectiveness of a curricular and professional development intervention at improving elementary teachers' science content knowledge and student achievement outcomes: Year 1 results. Journal of Research in Science Teaching, 51(5), 635-658. https://doi.org/10.1002/tea.21148

Erickson, F. (1986). Qualitative methods in research on teaching. In M. C. Wittroch (Ed.), Handbook of research on teaching (3. ed., pp. 162-213). Macmillan.

Eshach, H., \& Schwartz, J. (2006). Sound Stuff? Naïve materialism in middle- school students' conceptions of sound. International Journal of Science Education, 28(7), 733-764. https://doi.org/10.1080/09500690500277938

Grossman, P., Wilson, S., \& Shulman, L. (2005). Profesores de sustancia: el conocimiento de la materia para la enseñanza. Profesorado. Revista de currículum y formación del profesorado, 9(2), 1-24.

Gülçiçek, Ç., Kizilci, H., \& Damli, V. (2018). Effects of laboratory experiments on physics teacher candidates' wave concepts. Physics Education, 53(5), 055018. https://doi.org/10.1088/1361-6552/aacd80

Guthrie, J. T., Wigfield, A., \& VonSecker, C. (2000). Effects of Integrated Instruction on Motivation and Strategy Use in Reading. Journal of Educational Psychology, 92(2), 331-41. https://doi.org/10.1037/0022-0663.92.2.331

Harlen, W. (1997). Primary teachers' understanding in science and its impact in the classroom. Research in Science Education, 27, 323-337. https://doi.org/10.1007/BF02461757 
Harlen, W., \& Holroyd, C. (1997). Primary teachers' understanding of concepts of science: impact on confidence and teaching, International Journal of Science Education, 19(1), 93-105. https://doi.org/10.1080/0950069970190107

Herro, D., \& Quigley, C. (2017). Exploring teachers' perceptions of STEAM teaching through professional development: implications for teacher educators. Professional Development in Education, 43, 416-438. https://doi.org/10.1080/19415257.2016.1205507

Heywood, D. (2007). Problematising science subject matter knowledge as a legitimate enterprise in elementary teacher education. Cambridge Journal of Education, 37(4), 519-542. https://doi.org/10.1080/03057640701705856

Houle, M. E., \& Barnett, G. M. (2008). Students' conceptions of sound waves resulting from the enactment of a new technology-enhanced inquirybased curriculum on urban bird communication. Journal of Science Education and Technology, 17(3), 242-251. https://doi.org/10.1007/s10956-008-9094-6

Hrepic, Z., Zollman, D., \& Rebello, S. (2002). Identifying students' models of sound propagation. In S. Franklin, J. Marx, and K. Cummings (Eds.), Proceedings of 2002 Physics Education Research Conference. PERC Publishing. https://doi.org/10.1119/perc.2002

Hrepic, Z., Zollman, D., \& Rebello, S. (2010). Identifying students' mental models of sound propagation: the role of conceptual blending in understanding conceptual change. Physical Review Special Topics Physics Education Research, 6(2), 020114-1-18. https://doi.org/10.1103/PhysRevSTPER.6.020114

Kind, V. (2009). 'A conflict in your head': An exploration of trainee science teachers' subject matter knowledge development and its impact on teacher self-confidence. International Journal of Science Education, 31(11), 1529-1562. https://doi.org/10.1080/09500690802226062

Kitchen, J. A., Sonnert, G., \& Sadler, P. M. (2018). The Impact of Collegeand University-Run High School Summer Programs on Students' End of High School STEM Career Aspirations. Science Education, 102, 529-547. https://doi.org/10.1002/sce.21332 
Küçüközer, A. (2009). Prospective science teachers' understanding of sound. Procedia Social and Behavioral Sciences, 1(1), 1889-1894. https://doi.org/10.1016/j.sbspro.2009.01.332

Li, Y., Wang, K., Xiao, Y., \& Froyd, J. E. (2020). Research and trends in STEM education: a systematic review of journal publications. International Journal of STEM Education, 7(1). https://doi.org/10.1186/s40594-020-00207-6

Linder, C. J. (1993). University physics students' conceptualisations of factors affecting the speed of sound propagation. International Journal of Science Education, 15(6), 655-662. https://doi.org/10.1080/0950069930150603

Merino, J. (1998). Some difficulties in teaching the properties of sounds. Physics Education, 33, 101-104. https://doi.org/10.1088/00319120/33/2/014

Miles, M. B., \& Huberman, A. M. (1994). Qualitative data analysis: An expanded sourcebook (2. ${ }^{\mathrm{a}}$ ed.). Sage.

Moore, T. J., Tank, K. M., Glancy, A. W., \& Kersten, J. A. (2015). NGSS and the Landscape of Engineering in K-12 State Science Standards. Journal of Research in Science Teaching, 52(3), 296-318. https://doi.org/10.1002/tea.21199

Mosabala, M. (2014). The Teaching of Doppler Effect at Grade 12-Teacher's Content Knowledge. Mediterranean Journal of Social Sciences, 14(5), 207-213. https://doi.org/10.5901/mjss.2014.v5n14p207

Neuhoff, J., \& McBeath, M. (1997). Overcoming naive mental models in explaining the Doppler shift: an illusion creates confusion. American Journal of Physics, 65, 618-621. https://doi.org/10.1119/1.18618

Nilsson, P., \& Van Driel, J. (2011). How Will We Understand What We Teach? - Elementary Student Teachers' Perceptions of their Development of Knowledge and Attitudes Towards Physics. Research in Science Education, 41(4), 541-560.

Nowicki, B. L., Sullivan-Watts, B., Shim, M. K., Young, B., \& Pockalny, R. (2013). Factors influencing scientific content accuracy in elementary inquiry science lessons. Research in Science Education, 43(3), https://doi.org/1135-1154. 10.1007/s11165-012-9303-4 
Pejuan, A., Bohigas, X., Jaén, X., \& Periago, C. (2012). Misconceptions about sound among engineering students. Journal of Science Education and Technology, 21(6), 669-685. https://doi.org/10.1007/s10956-011-9356-6

Rice, D. (2005). I didn't know oxygen could boil! What preservice and inservice elementary teachers' answers to 'simple' science questions reveals about their subject matter knowledge. International Journal of Science Education, 27(9), 1059-1082. https://doi.org/10.1080/09500690500069426

Ring, E. A., Dare, E. A., Crotty, E. A., \& Roehrig, G. H. (2017). The evolution of teacher conceptions of STEM education throughout an intensive professional development experience. Journal of Science Teacher Education, 28(5), 444-467. https://doi.org/10.1080/1046560X.2017.1356671

Rollnick, M., \& Mavhunga, E. (2016). The place of subject matter knowledge in teacher education. In J. Loughran \& M. L. Hamilton (Eds.), International handbook of teacher education (pp. 423-452). Springer. https://doi.org/10.1007/978-981-10-0366-0 11

Saraiva, C. (2013). Reflexão e absorção do som. Gazeta de Física, 36(1), 1820.

Schwab, J. J. (1964). The structure of the disciplines: meanings and significances. In G. W. Ford \& L. Pugno (Eds.), The structure of knowledge and the curriculum (pp. 6-30). Rand McNally.

Shahali, E., Halim, L., Rasul, M., Osman, K., \& Zulkifeli, M. (2017). STEM learning through engineering design: Impact on middle secondary students' interest towards STEM. EURASIA Journal of Mathematics Science and Technology Education, 13(5), 1189-1211. https://doi.org/10.12973/eurasia.2017.00667a

Shulman, L. S. (1987). Knowledge and teaching: Foundations of the new reform. Harvard Educational Review, 57, 1-22.

Toma, R. B., \& Greca, I. M. (2018). The effect of integrative STEM instruction on elementary students' attitudes toward science. Eurasia Journal of Mathematics, Science and Technology Education, 14(4), 1383-1395. https://doi.org/10.29333/ejmste/83676 
Viennot L., \& Leroy, J. L. (2004). Doppler and Romer: what do they have in common? Physics Education, 39(3), 273-280.

Wang, X. (2013). Why Students Choose STEM Majors: Motivation, High School Learning, and Postsecondary Context of Support. American Educational Research Journal, 50(5), 1081-1121. 